\title{
Does the unification of health financing affect the distribution pattern of out-of-pocket health expenses in Turkey?
}

Cinaroglu S., Baser O. Does the unification of health financing affect the distribution pattern of out-of-pocket health expenses in Turkey?

Turkey has implemented health reforms for over a decade and has taken significant steps toward unifying health financing. This study investigated the financial burden associated with out-of-pocket (OOP) expenditures under universal health coverage, using national 2003-2015 household budget data from the Turkish Statistical Institute. Progress was evaluated using Kakwani-Suits indices and Lorenz concentration curves. The results indicate that overall, more than a decade after its unification, redistribution of wealth in the Turkish health financing system has benefitted the wealthy but not the poor. Both curve and index approaches (Kakwani index $2003=-0.50 ; 2015=-0.44$ ) reveal an increasingly regressive pattern of OOP health expenditures. The effective use of fiscal space and good political leadership are essential for the successful continuation of reforms to combat poverty in Turkey.

\author{
Songul Cinaroglu ${ }^{1}$ (D) , Onur Baser ${ }^{2,3}$ \\ ${ }^{1}$ Faculty of Economics and Administrative Sciences (FEAS), \\ Department of Health Care Management, Hacettepe University, \\ Ankara, Turkey \\ ${ }^{2}$ Economics Department, MEF University, İstanbul, Turkey \\ ${ }^{3}$ Internal Medicine, University of Michigan, Ann Arbor, MI, USA
}

Key words: out-of-pocket health expenditures, health care, health reform, unification of health financing system, poverty alleviation, poverty, Turkey

Songul Cinaroglu, Faculty of Economics and Administrative Sciences (FEAS), Department of Health Care Management, Hacettepe University, Beytepe, Ankara, 06800, Turkey E-mail: cinaroglus@hacettepe.edu.tr

Accepted for publication January 16, 2019

\section{Introduction}

Poverty is a dynamic phenomenon, with poverty alleviation strategies at the top of the agendas of policymakers and practitioners in health care (Atun, Chaumont, Fitchett, Haakenstad, \& Kaberuka, 2016; Deaton, 2003). Poverty alleviation strategies, simultaneously supported by effective health and economic policies, reduce poverty and improve the health of those living in poverty (Atun et al., 2016). The health care reforms undertaken by many countries during the past decade have led to improved health outcomes and have helped to create an equitable financing system (Wagstaff, 2002). Historically, the Turkish health system has undergone reforms. Since the 1980s, Turkish health reforms have followed international trends, which in most cases have improved efficiency and controlled costs in health systems. After the Socialization of Health Services Delivery Act in 1961, Turkish health care developed significantly. The main emphasis of this reform was to provide health services to the entire population, based on equity. However, socialized health services have suffered severely from limited financial resources over time. Country-wide health care was socialized in 1984, and the Act's socialization model remains in force (OECD \& WB, 2008). While the Turkish Government supported the Socialization Act and made efforts to improve primary care services, fundamental changes to the system were not made until the late 1980s. During 1980-1983, Turkey was governed by military rules, wherein the government's role in health care was redefined, with structural adjustments and protection for the poor from financial risk becoming primary government goals. Supportive policies began in the early 1980s with private health investments subsidizing private medical care. The military government then announced additional privatization of the health care sector. During the late 1980 s, health reforms were supported by international organizations, such as the World Health Organization (WHO) and the World Bank (WB). The first project in 1988 was drafted to develop primary health care in Turkey. After these efforts, with the technical support of WHO experts, Turkey joined an adoption of regional health targets for all European countries in 1989. A National Health Policy (NHP), prepared in 1993, was revised by the Turkish Ministry of Health $(\mathrm{MoH})$, with political support from all parties, which determined the document's main objectives. The system focused on decentralized health management, family medicine for primary health care services, an autonomous secondary and tertiary health care system, a General Health Insurance (GHI) system, and competition in the health market (OECD \& WB, 2008; YenimahalleliYasar, 2011). The sixth, seventh, and eighth five-year 
development plans (covering 1990-1995, 1996-2000, and 2001-2005, respectively) are coherent with NHP. The seventh plan strengthened the $\mathrm{MoH}$ and introduced the GHI system. Scholars suggest that, apart from the Green Card system, the only program accomplished after the NHP document was the promotion of private sector investment (Agartan, 2012; OECD \& WB, 2008; Yenimahalleli-Yasar, 2011). Initially set up in 1992, the important Green Card program, which provided social protections, was financed by general revenues. Before 2002, the program's budget and coverage were small (Y1ldırım \& Yildırım, 2011). In 2002, the government launched its Urgent Action Plan through the Health Transformation Program (HTP). The main goals of this program were the reorganization of $\mathrm{MoH}$, coverage of all citizens by GHI, the moving of all health institutions under one umbrella, introduction of a family medicine model, promotion of the private health sector (giving special importance to mother and child care), and effective human resource management. These objectives constituted the main components of HTP, which was launched in 2003. To establish a high-quality and effective health system while considering equity was one of the main targets of this system. On the agenda since the 1980s, Turkey's health care system has failed to provide universal coverage, due mainly to a high level of informal employment. To address this problem, in the early 1990s a new form of social assistance was introduced, the Green Card program, which offered free inpatient health care services for the very poor and was funded by the general budget. In 2000, Green Card expenditures reached one-fourth of all public expenditures on health care services $(\mathrm{MoH}$, 2004).

Starting in 2003, Turkey's health care reforms have aimed at achieving universal health coverage (Atun et al., 2013). Previously, Turkey had a fragmented health financing system, which caused regional disparities in health care throughout the country (Erus, YakutCakar, Cali, \& Adaman, 2015). Since then, health care has received substantial assistance from the Turkish Government (Pearson, Colombo, Murakami, \& James, 2016). Total health care expenditures, as a proportion of gross domestic product (GDP), increased from 5.3\% in 2003 to $6.1 \%$ in 2008 , with almost three-quarters of this amount coming from the public sector (Atun et al., 2013). Despite growing faster than the Organization for Economic Co-operation and Development (OECD) average, the share of total health expenditure in Turkey, which is the lowest among OECD countries, accounted for 5.1\% of GDP in 2013, well below the OECD average of $9 \%$ (Pearson et al., 2016). According to the WB (2014), because economic growth in Turkey has been socially inclusive, the impact of the country's health care reforms deserves scholarly attention. Certainly, access to basic services, such as health care and education, has improved. The average number of primary health care consultants increased from 1.75 to 2.83 per person per year between 2002 and 2013 (Hone et al., 2017). To support this statement, more than a decade of health care reforms have led to major improvements in the health of the population, accessibility, and quality of care (Okem \& Cakar, 2015). One of the HTP's goals is to improve the health status of the population. As a consequence, average life expectancy in Turkey rose by 4 years between 2003 and 2013, and exceeds the OECD country country average, increasing from 70 years in 2000 to 75.18 years in 2013 (Pearson et al., 2016). Infant mortality in the country also has improved significantly. The infant mortality rate decreased from 31.5 deaths per 1,000 births in 2002 to 7.7 deaths per 1,000 births in 2011. Similarly, the annual neonatal mortality rate per 1,000 live births was 52.6 deaths in 1993, 17 deaths in 2008, and 5 deaths in 2014 (TurkStat, 2015).

Accessibility is another major component of HTP. Providing equal access to health care is one of the magic triad of HTP. However, knowledge is limited about HTP's effect on access to care. A recent study suggests that health reform has improved overall access to health care services in Turkey, but that, because of cost increases in 2013, 9\% of the population still has unmet needs, even after the implementation of universal health coverage (Yardim \& Uner, 2018). HTP have also improved the quality of care, primarily through the introduction of family medicine physicians. Consequently, hospital outcome quality, as measured by patient satisfaction, improved from 39.5 to $73.1 \%$ between 2003 and 2010 (Cesur, Gunes, Tekin, \& Ulker, 2017). A rapid decline in poverty and growth of the middle class also indicate important improvements (Seker \& Jenkins, 2015). However, global economic conjuncture has a negative effect on the Turkish welfare system, in the long run.

Due to the global recession, poor economic results in Turkey were observed starting in 2007. Average per-capita income growth for 2007-2014 declined to approximately $3 \%$, markedly lower than the $6 \%$ growth during 2002-2006. These drops in income began before the global economic crisis in late 2008 . Economic growth in 2007 was an unimpressive 4.7\%, and this slowdown continued through 2008, even before the global crisis hit. These poor results were attributed to minimal private and technological investment, low productivity, and consumption-based economic growth (Acemoglu \& Ucer, 2015). Despite poor economic growth since 2007, Turkey's health reforms have continued for over a decade, beginning in 2003. Pamuk (2007) defended the idea that economic growth during 2002-2007 created a fiscal environment that supported financial protection strategies in health care. The effects of this reformist environment on poverty 
and on household health expenditures over time are of particular importance to scholars. Researchers who have examined national Turkish Household Budget Survey (HBS) data for 2003 (before the reforms) and 2006 (after the reforms) state that the reformist environment had increased the ratio of households with nonzero out-of-pocket (OOP) health expenditures (Erus \& Aktakke, 2012). Furthermore, a lower proportion of households faced catastrophic health expenditures during the periods between 2003, 2006, and 2009 (Yardım, Cilingiroglu, \& Yardım, 2014).

Turkey's health reforms provide financial protection, particularly to disadvantaged population groups (Atun et al., 2016). A better fiscal environment, created by Turkey's sustained economic growth, has enabled the government to increase health expenditures (Atun et al., 2013). Before these health reforms, Turkey's health care system relied on separate public insurance plans that combined retirement pensions with health insurance. These plans' revenues were collected from both employees and their employers. It is evident that before health reform, the government did not provide financial support to people who did not formally work and were not covered by medical insurance (Akdag, 2011; Y1lmaz, 2013). In 2000, more than one-fourth of all Turkish health care expenditures were OOP (Okem \& Cakar, 2015). The fragmented structure of the health insurance system, along with inequalities and increases in OOP health expenditures (Atun et al., 2013), raised concerns about the financial sustainability of the Turkish health care system. Thus, the health system's reform took great interest in stakeholders (Akınc1, Mollahaliloglu, Gursoz, \& Ogucu, 2012). Given these circumstances, financial inclusion and poverty alleviation strategies have been implemented since 2003. Radical changes under Turkey's health reforms include the introduction of compulsory health insurance, unification of different health insurance plans under the Social Security Institution (SSI), and harmonization of benefits and reimbursement rules. Additionally, improvements in the Green Card project, which protects the poor, and an increase in contributory payments were also employed (Okem \& Cakar, 2015). With poverty alleviation strategies contributing to redistributions in the health care system, social inequalities have started to decline (Atun et al., 2016).

Complementary Health Insurance (CHI) then came into effect in October, 2013 (UT, 2013). According to the Insurance Association of Turkey (IAT), the CHI market has growth potential. Private health insurance companies' premium income increased by $7.78 \%$ between 2014 and 2015 (IAT, 2015). CHI is a cost-sharing mechanism, which may present barriers to access for people in low-income groups and for those above the threshold for cost-sharing exemptions (Thomson \& Mossialos, 2004). The literature suggests that the main motivation for purchasing $\mathrm{CHI}$ is protection against the financial risk associated with co-payments in public health insurance (Grignon \& Kambia-Chopin, 2009). However, this policy increases households' risk aversion and the intention of insured individuals to spend more on health care services (Schneider, 2004). Moreover, this policy has the potential to increase the gap in OOP health expenditures between poor and wealthy population groups. Since the poorest individuals cannot afford complementary insurance that covers user charges, $\mathrm{CHI}$ is often more available to higher-income individuals (Thomson \& Mossialos, 2004). In other words, in the long run, CHI will increase the moral hazard risk in the health insurance market, and the burden of OOP health expenditures will fall on low-income population groups. This indicates the regressive pattern of OOP health expenditures and threatens the financial sustainability of the health financing system (Grignon, Perronnin, \& Lavis, 2008; Schneider, 2004).

To date, two studies have analyzed the distribution of OOP health expenses in Turkey, using Turkish HBS data. One of these studies, conducted using the Kakwani index, found that OOP health expenditures exhibited a regressive pattern during 2003-2005, the first years of health reform $(\mathrm{Oz}, 2008)$. However, the second study, which utilized the same data and index, observed a progressive pattern for the years 2003, 2006, and 2009, and stated that OOP health expenditures declined over these years (Yardım et al., 2014). Both empirical studies refer to time periods before unification of the health financing system took place and fragmented health insurance system problems began to be solved. In light of recent studies that have emphasized the need for further research to identify this regressive OOP pattern (Atun et al., 2016; Okem \& Cakar, 2015), the present study examined the financially burdensome distribution of OOP health expenditures in Turkey caused by the unification of the health financing system.

The remainder of this article is organized as follows. The next section provides an overview of the health system, the health financing system, and health reform in Turkey, followed by a description of the methods used to analyze the household distribution of OOP health expenses. The third section presents the methods used in this study, the fourth section outlines the study's results, and the fifth and last section makes recommendations for future research.

Overview of health reforms, unification of the health financing system, and poverty alleviation in Turkey

Since 2003, Turkey's health care system has experienced radical transformations. Health reforms were 
expected to improve the effectiveness, efficiency, and equality of access to health care services (Y1lmaz, 2013). A low level of health expenditures and an inequitable health system were the primary financial shortcomings of the country's health system during the pre-reform period (Atun et al., 2013). The health care reforms enabled significant improvements in general health and health outcomes. Remarkable decreases were observed in the mortality rates of children under the age of five and of pregnant women. For the former, mortality rates (per 1,000 live births) decreased from 39.6 deaths in 2000 to 17 deaths in 2014. Maternal mortality (per 100,000 live births) decreased from 79 deaths in 2000 to 14.3 deaths in 2014 (Atun et al., 2016). However, health systems should not only ensure good health but should also protect households from the financial consequences of poor health. Thus, optimal and equitable delivery of health care services is essential for a sustainable health system (Wagstaff \& Lindelow, 2008).

Turkey established public health insurance and has been developing its capacity for health care service delivery since the late 1940s. Prior to the health reforms, the country experienced inequalities in health financing (Yilmaz, 2013). The following points about inequalities in pre-reform health financing are worth highlighting. Formerly, the public insurance market had a fragmented structure and was stratified by differences in status in Turkey's labor market (Bugra \& Keyder, 2006; Y1lmaz, 2013). Inequalities existed between the beneficiaries of public insurance plans and "outsiders" who made informal payments (Tatar \& Kanavos, 2006). Before 2006, the level of coverage and quality of care varied among different beneficiaries of the health insurance system, and health benefits were based on employment status. Although the Green Card program provided uninsured people with access to doctors and hospitals within the social security system, it did not cover medicines. Institutional studies have concluded that only a small percentage of the population benefited from medical coverage. HBS data indicate that more than a third of the population still remain without health insurance coverage and have to pay for their health needs themselves. This category also represents Green Card program beneficiaries. Given these circumstances, the government's health expenditures have been rising. To this end, the government introduced comprehensive "health financing system reform" into its agenda (Bugra \& Keyder, 2006). Following changes in the Green Card program, this reform process has provided a new welfare regime for Turkey, aimed at providing universal health coverage and reducing the proportion of the population without health insurance. The Green Card program was established in 1992 as a means-tested mechanism, financed by general taxation, to grant poor people access to health care services as a poverty alleviation strategy. Green Card coverage and benefits expanded between 2003 and 2008. Over the years, the Green Card program's budget has increased with its number of beneficiaries (Aran \& Hentschel, 2012; Bugra \& Candas, 2011; Erus et al., 2015). Turkey's pre-reform health system was comprised of five forms of public insurance: the Social Insurance Organization (Sosyal Sigortalar Kurumu [SSK]), the General Employees Retirement Fund for Civil Servants (Emekli Sandiğ [ES]), the Pension Fund for the Self-Employed (Esnaf, Sanatkarlar ve Diğer Bă̆ımsız Çalısanlar Sigortalar Kurumu, Bağ-Kur), the Active Civil Servants Insurance Fund, and the Green Card program (Akdag, 2011). In 2006, Universal Health Insurance (UHI) was adopted as part of broader social security reform. Reorganization of the health financing system continued in 2008 with the establishment of the SSI for financial pooling and purchasing. With these regulations, the Social Insurance Organization, the Pension Fund for the Self-Employed, and the General Employees Retirement Fund for Civil Servants joined the SSI (Akdag, 2011). These considerable changes reduced the prevalence of informal payments and filled the gap between different occupational statuses in terms of health expenditures (Agartan, 2008, 2012; Wendt, Agartan, \& Kaminska, 2013; Y1lmaz, 2013).

After 2007, Turkey was affected by the global financial crisis. Its economic growth became sluggish and there was a decrease in the number of employed and insured people. In 2010, premium revenues met only $60 \%$ of SSI spending, and because of the decrease in premium revenues and budget transfers of more than $5.03 \%$ from the government to the SSI, the government began implementing co-payments to restrict outpatient and in-hospital visits for medical care (Okem \& Cakar, 2015; Y1lmaz, 2013). One of the most important poverty alleviation strategies concerned the Green Card, the benefits of which were expanded to include outpatient visits and pharmaceuticals (Atun et al., 2016). Moreover, expansion of the Green Card program increased insurance coverage for the poorest groups, from 2.4 million people in 2003 to 10.2 million in 2011 (Okem \& Cakar, 2015). In 2012, when the Green Card program joined the SSI, a unified social insurance system was fully realized. Expansion of the Green Card program helped reduce catastrophic health expenditures (Yardim et al., 2014). During that time, informal payments were another problem contributing to the unsustainability of Turkey's health care system (Elveren, 2008). Previous literature has emphasized that informal payments, an important part of OOP in Turkey, accounted for $25 \%$ of 2002 health expenditures. Most informal payments were made for surgical services, with surgeons asking for extra money as a "knife fee" for performing a 
surgery. A physician's private office was the principal physical setting for informal payments (Tatar, Ozgen, Sahin, Belli, \& Berman, 2007). In 2010, a law was enacted to prevent public physicians' dual practice in private health centers (Okem \& Cakar, 2015), thereby protecting patients from having to make informal payments. Overall, unification of health financing, poverty alleviation by implementing universal coverage, improvement of the Green Card program, equalization of different insurance beneficiaries, and the abolishing of physicians' dual practices have enabled the government to fix the disintegrated health insurance system, reducing informal payments and allowing equal distribution of financial risk in OOP health care expenditures. Comprehensive improvements in Turkey's medical financing market were valuable in measuring the distribution of OOP health expenditures under health financing unification. The following section presents measurement tools used to examine the distribution of OOP health care expenditures.

\section{Measuring the distribution of the financial burden of OOP health expenditures}

Lorenz analysis is the traditional method for detecting departures from proportionality and identifying their location in the ability-to-pay distribution. However, it does not provide a measure of the degree of progressivity, which is useful in making comparisons across time or countries (Lambert, 1993). The Kakwani index is the most commonly used progressivity measure in general and health economics literature. It is a popular index used to measure the distribution of financial burden of OOP health expenditures (Kakwani, 1977;
Wagstaff \& van Doorslaer, 1992). The Kakwani index is twice the area between the Lorenz and concentration curves. It is illustrated in Figure 1a and is represented as follows:

$$
\pi_{K}=C-G
$$

In equation (1), "C" is the concentration index for health expenditures and " $G$ " is the Gini coefficient of the ability-to-pay variable (Wagstaff \& van Doorslaer, 1992; Wagstaff, van Doorslaer, \& Paci, 1989). The Gini coefficient measures inequality among different income levels in a population. If income is distributed equally, the Gini value is 0 , and if one person has all the income, the Gini coefficient is 1 . The Gini coefficient is illustrated using the Lorenz curve. On the horizontal axis, the population is classified into groups ranked in the ascending order of their income. The vertical axis shows the total proportion of income increasing in each group within that community. The Lorenz curve indicates the area below the $45^{\circ}$ line of equality as lower income groups in the income distribution earn less than their equal shares. The degree to which the Lorenz curve deviates from the $45^{\circ}$ line of equality is a measure of income inequality. The Gini coefficient is the ratio of the area between the Lorenz curve and the $45^{\circ}$ line of equality (Kakwani, 1977; Wagstaff et al., 1989). It is accepted that OOP expenses are progressive when the concentration curve lies below the Lorenz curve. An increasing deviation of the concentration curve from the Lorenz curve in the downward direction indicates a more progressive OOP pattern (De Maio, 2007). The Kakwani index value, $\pi_{\mathrm{k}}$, ranges from -2 to 1 . A negative number (a)

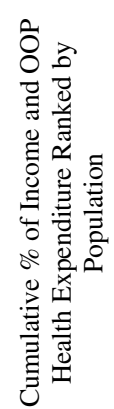

0$$
\begin{aligned}
& 0 \\
&
\end{aligned}
$$

$$
\text { Cumulative } \% \text { of Population }
$$

(b)

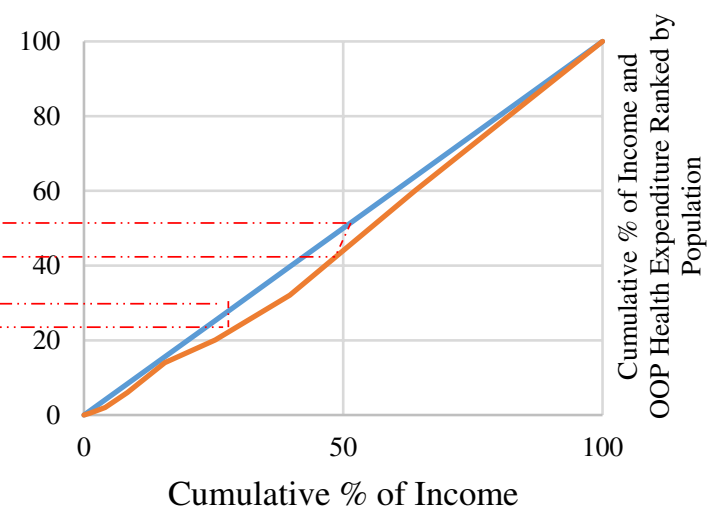

Concentration Curve 1

Concentration Curve 2

Figure 1. Kakwani and Suits indices of progressivity.

Source: Wagstaff and van Doorslaer (1992). 
indicates regressivity while a positive number indicates progressivity. In the case of proportionality, the concentration curve lies on the top of the Lorenz curve, and the index is zero (Kakwani, 1977; O'Donnell, van Doorslaer, Wagstaff, \& Lindelow, 2008; Wagstaff et al., 1989). An alternative to the simple Kakwani index is the Suits index, which gives greater weight to the deviations from proportionality that occur among households higher up in the ability-to-pay distribution (Suits, 1977). The Suits index is based on what Lambert and Pfähler (1988) called "relative concentration curves." This is defined as twice the area between concentration indexes, and is represented as $\pi_{\mathrm{S}}$ (see Figure 1b). If the tax system is progressive, $\pi_{\mathrm{S}}$ is positive. In contrast, if the system is regressive, $\pi_{\mathrm{S}}$ is negative. The value of $\pi_{\mathrm{S}}$ ranges from -1 (when the entire financial burden falls on the poorest person) to 1 (when the entire financial burden falls on the richest person) (Wagstaff \& van Doorslaer, 1992).

Anderson, Roy, and Shoemaker (2003) developed an alternative formula to calculate the Suits index. It is written as follows:

$$
\begin{aligned}
S & =1-(1 / 5,000) \int_{0}^{100} T(Y) d y \\
& \approx 1-(1 / 5,000) \sum_{i=0}^{i=n}\left[T\left(Y_{i}\right)+T\left(Y_{i-1}\right)\right]\left[Y_{i}-Y_{i-1}\right]
\end{aligned}
$$

In equation (2), $Y$ and $T(Y)$ are the aggregate percentage of the total income and the cumulative percentage of the tax burden (OOP health expenditure burden), respectively. The $(1 / 5,000)$ term represents the area of the triangle below the line of proportionality whose legs are both $100 \%$. In reality, the cumulative distribution of $T(Y)$ is often only available for a few discrete values of $Y$ (Anderson et al., 2003).

\section{Methods}

\section{Data set and analysis}

The data for this study were obtained from the HBS conducted by the Turkish Statistical Institute (TurkStat) for the period 2003-2015. HBS is a national survey focused mainly on consumption expenditure. Moreover, household size and type as well as income and expenditure groups are considered in the survey. Data are collected from a representative stratified clustered sample of households. The total number of households in the survey and total number of households that reported OOP health expenditure for the period 2003-2015 are presented in Table 1. Surveys were conducted between the periods of January 1 to December 31, for all study years, along with face-to-face interviews. All consumption expenditures of the sample households, including health expenditures, were recorded in diaries by interviewers while the interview was in progress. Consumption expenditures and income included goods and services, such as food and nonalcoholic beverages, clothing, water, housing, and electricity. Health expenditures included medical products and outpatient and inpatient hospital services (TurkStat, 2015). Sampling weights provided from the data files were applied to each year's data to generate nationally representative results. All price values were deflated using consumer price index (CPI) values for all items. The year 2003 was used as a base year for deflation. CPI values for health expenditure items are also presented in Table 1. Before the analysis, Turkish lira values were converted into 2003 prices using the CPI levels for monthly expenditures.

The Kakwani and Suits indexes were calculated using the "Inequality and Concentration Indices and Curves-IC2" package in the R program. "IC2" allows for the computation of the inequality and concentration indexes. It also calculates the Gini and concentration indices and enables us to determine the Kakwani index values (Plat, 2015). The Suits index was calculated using a methodology developed by Anderson et al. (2003). The Excel program was used to illustrate the Lorenz and concentration curves and visualize the burden of OOP health expenditures on households. The Lorenz curve is a measure of the distribution of wealth that is used to explore the effects of a changing poverty line (Morton, 2010). In our study, we call them Lorenz curves for capacity to pay (CTP). We follow Xu's (2005) methodology to define CTP and examine the burden of OOP health payments. A household's CTP is defined as the non-subsistence effective income of the household. Subsistence expenditure (SE)

\begin{tabular}{|c|c|c|c|c|c|c|c|c|c|c|c|c|c|}
\hline \multirow{2}{*}{ Variables } & \multicolumn{13}{|l|}{ Years } \\
\hline & 2003 & 2004 & 2005 & 2006 & 2007 & 2008 & 2009 & 2010 & 2011 & 2012 & 2013 & 2014 & 2015 \\
\hline $\begin{array}{l}\text { Total number of households } \\
\text { in the survey }\end{array}$ & 25,764 & 8,544 & 8,559 & 8,558 & 8,548 & 8,549 & 10,046 & 10,082 & 9,918 & 9,987 & 10,060 & 10,122 & 11,491 \\
\hline $\begin{array}{l}\text { Number of household's that } \\
\text { reported 0OP health } \\
\text { expenditures }\end{array}$ & 10,512 & 3,898 & 4,335 & 4,501 & 4,375 & 4,625 & 5,956 & 6,423 & 6,366 & 6,358 & 7,112 & 6,713 & 6,801 \\
\hline CPI values* & 100.4 & 112.2 & 111.7 & 120.6 & 121.6 & 124 & 127.1 & 127.8 & 128.2 & 130.4 & 136.7 & 148.5 & 159.1 \\
\hline
\end{tabular}

Table 1. Total number of households, households that reported OOP health expenditures, and CPI values for health expenditure items.

${ }^{*} \mathrm{CPI}$ values include all health-related items, including medical products, and outpatient and inpatient health expenditures. To compare consumption internationally, in 20031.49 Turkish Liras = 1 US \$ (Average), (Central Bank of the Republic of Turkey-CBRT, 2018, http://www.tcmb.gov.tr/). 
is the minimum requirement to maintain basic life in a society. Nevertheless, some households may report food expenditure (FOOD) that is lower than subsistence spending. This indicates that the household's food expenditure is less than the estimated poverty standard for that country. This situation could also be because the reported food expenditure in the survey does not include food subsidies, self-production, and other noncash means of food consumption. In this instance, nonfood expenditure is used as nonsubsistence spending $(\mathrm{Xu}, 2005)$. The formulation of CTP is as follows:

$$
\begin{gathered}
\mathrm{CTP}=\mathrm{EXP}-\mathrm{SE}, \text { if } \mathrm{SE} \leq \mathrm{FOOD} \\
\mathrm{CTP}=\mathrm{EXP}-\mathrm{FOOD}, \text { if } \mathrm{SE}>\mathrm{FOOD}
\end{gathered}
$$

The burden of OOP health payments (OOPCTP) is defined as the OOP health payments as a percentage of a household's CTP:

$$
\text { OOPCTP }=\frac{\text { OOP }}{\mathrm{CTP}}
$$

\section{Results}

\section{Descriptive statistics}

Table 2 presents the descriptive statistics of the study variables. The mean monthly OOP health expenditures per household increased gradually from 2003 to 2015 . Additionally, the average monthly OOP health expenditures of households increased 3 times between 2003 and 2015. The average CTP concurred with the average monthly OOP health expenditures and increased during these periods. Moreover, the OOP health expenditure share of CTP displayed a mildly increasing trend, increasing from $2.84 \%$ in 2003 to $4.07 \%$ in 2014 .

\section{The Kakwani and Suits indexes}

Figure 2 presents the Gini and concentration index values and the Kakwani index results. The Kakwani index values were negative from 2003 to 2015. In other words, OOP health expenditures regressed over the study period. The Kakwani index values changed from -0.50 in 2003 to -0.44 in 2015 . This regressive pattern indicates a pro-wealthy (inequity-increasing)

Table 2. Descriptive statistics.

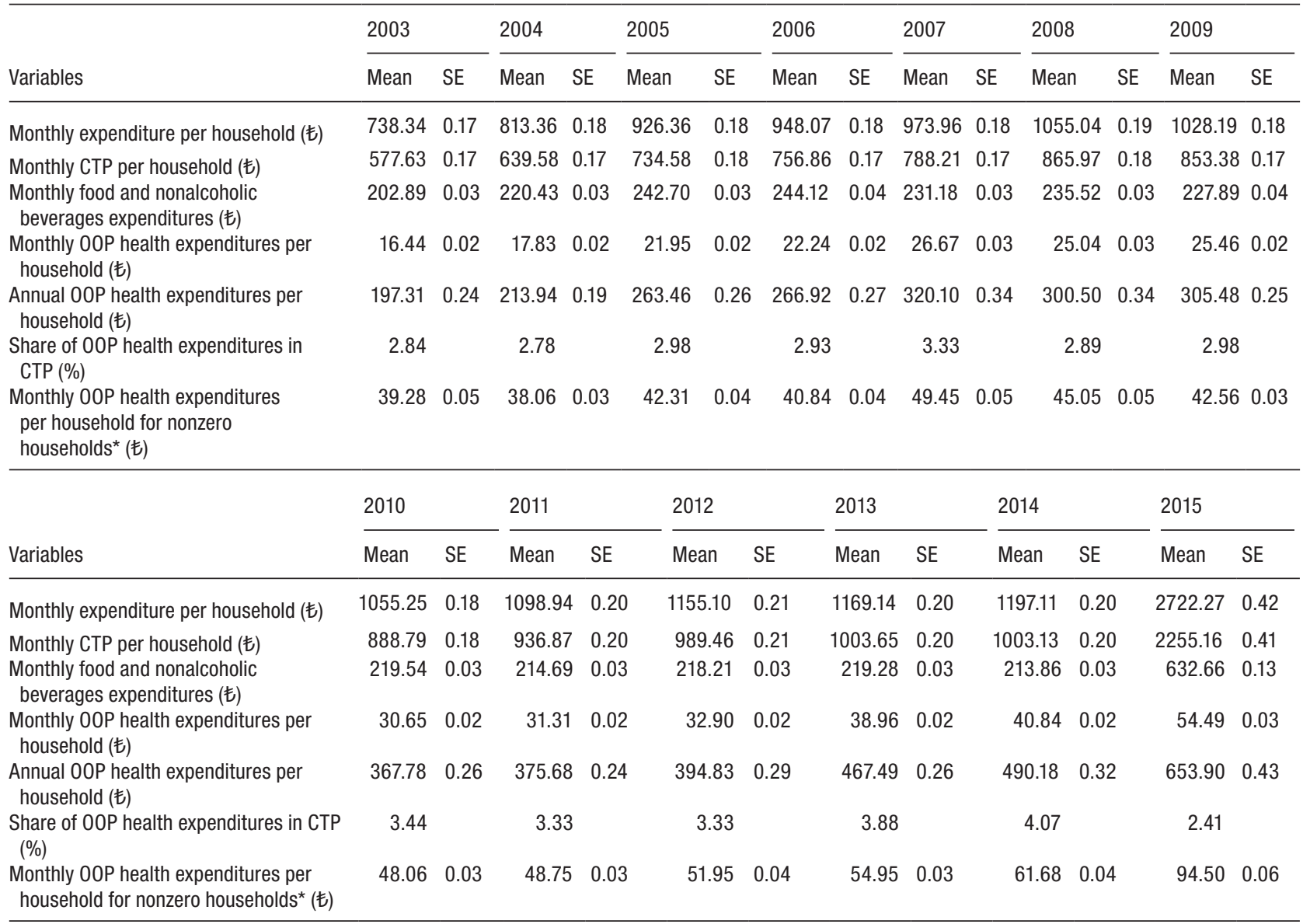

OOP, out-of-pocket; CTP, capacity-to-pay; SE, standard error; $€$, Turkish Liras*: Nonzero households refers to the households made nonzero 00P health expenditure. 


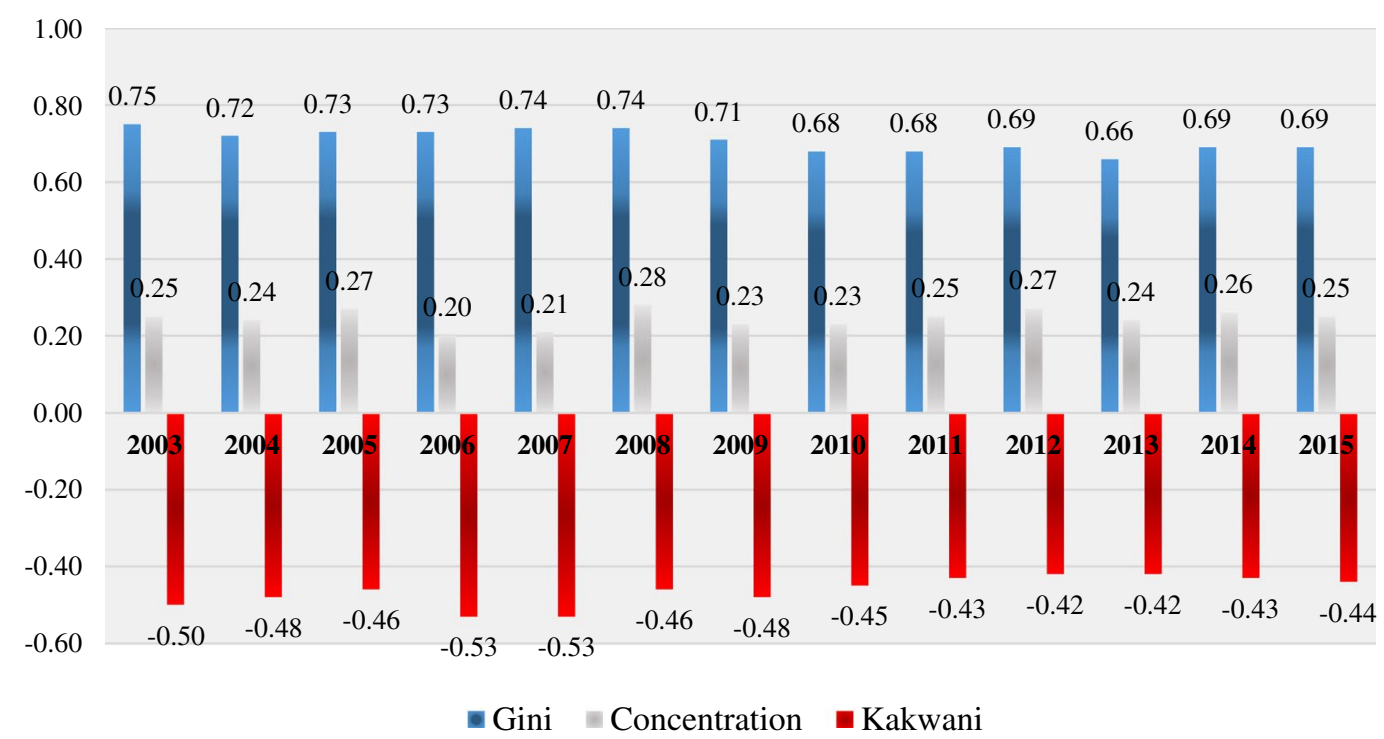

Figure 2. Gini, concentration and Kakwani indices.

distribution of the financial burden of OOP health expenditures. In other words, the financial burden of OOP health expenditures fell on the shoulders of the poor households in terms of the Kakwani index.

Figure 3 presents the Suits index results and the comparative calculated values of the two progressivity indices. In the Suits index, similar to the Kakwani index, positive values indicate progressivity while negative values indicate regressivity. The Suits index results show that the financial burden of OOP health expenditures had a progressive pattern for the period 2003-2015. The Suits index values changed from 0.00 in 2003 to 0.01 in 2015. It is clear that the degree of progressivity decreased over the study period. The decreasing progressive pattern indicates a pro-wealthy (inequity-increasing) distribution of the financial burden of OOP health expenditures.

\section{Lorenz and concentration curves}

The Lorenz and concentration curves for the years 2003, 2008, and 2013 are shown in Figures 4-6, respectively, under the assumption of no lagged impact of the HTP on itself and no true effect of HTP on the distribution pattern of OOP health expenditures for the years chosen. The transformation of the health care system began in 2003 and the SSI for financial pooling and purchasing was established in 2008. Subsequently, Green Card schemes were included in the social security system as a poverty alleviation measure. The Lorenz and concentration curves for year 2013, half a decade later, show the poverty reduction strategies. The distributive pattern of OOP health expenditures is expected to change in future.

Figure 4 presents a Lorenz curve for CTP and a concentration curve for OOP health expenditures for
2003. The OOP health expenditures become more progressive when the concentration curve lies below the Lorenz curve. Figure 4 indicates a predominantly progressive pattern of OOP health expenditures in 2003. In other words, the distribution of the financial burden of OOP health expenditures fell on the shoulders of the wealthy households.

Figure 5 presents a Lorenz curve for CTP and a concentration curve for OOP health expenditures for 2008. The progressive pattern of OOP expenditures continued in 2008; however, the degree of progressivity decreased. This trend shows that OOP spending on health was less progressive than in 2003, relative to the increases in CTP.

Lastly, Figure 6 shows a Lorenz curve for CTP and a concentration curve for OOP health expenditures on health for 2013. It is interesting that, with more than a half a decade of implementing the unification of the health financing system and poverty alleviation measures, the least regressive pattern began to appear. This indicates a change in the observed progressive pattern and the existence of inequalities in the financial burden distribution of OOP health expenditures in Turkey. In other words, OOP spending on health has become regressive relative to the increase in CTP.

\section{Discussion}

Turkey is a middle-income country that has undergone comprehensive health reform and has realized its goal of a unified health financing system. More than a decade has passed since the establishment of Turkey's ambitious health reforms (Yardım et al., 2014), the primary objective of which was to unify the health financing system by introducing GHI (Erus et al., 2015). 


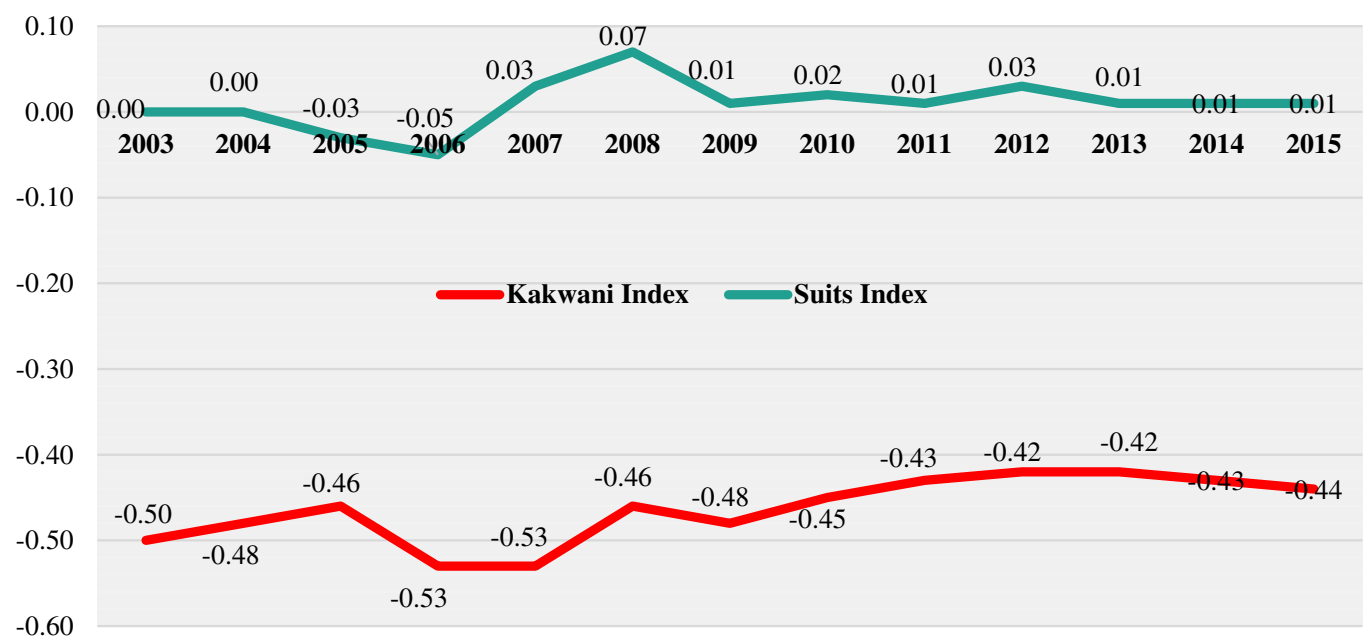

Figure 3. Progressivity indices for out-of-pocket expenditures on health.

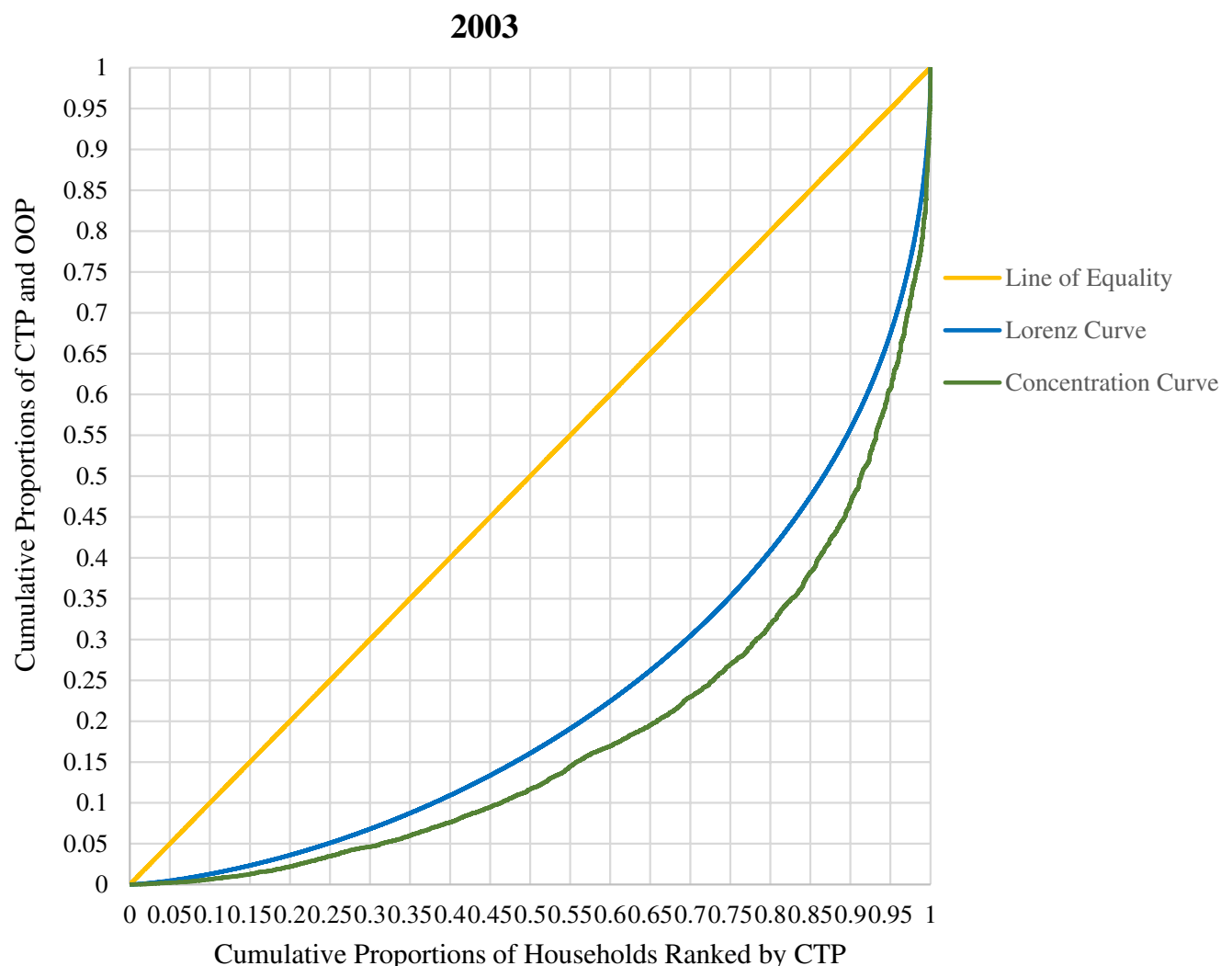

Figure 4. Lorenz and concentration curves for the year 2003. OOP, out-of-pocket health expenditure; CTP, capacity to pay.

The introduction of compulsory social health insurance, incorporating performance-related payments, restructuring health service delivery using family medicine, and strengthening the MoH's governing role were the other main components of this reform (Okem \& Cakar, 2015). After these reforms, Turkish citizens were covered under a publicly run, single-payer health insurance system that provided equal access to health benefits (Sparkes, Bump, \& Reich, 2015).
Turkey had attempted to establish a national health insurance system before 2003, but without political support, these experiments failed to achieve universal coverage and to protect poor populations (Sparkes et al., 2015; Yenimahalleli-Yasar, 2011). The Green Card program, though, did protect financially disadvantageous groups. In 1992, Turkey launched its noncontributory Green Card health insurance program to provide health services to the poor who were not covered by health 


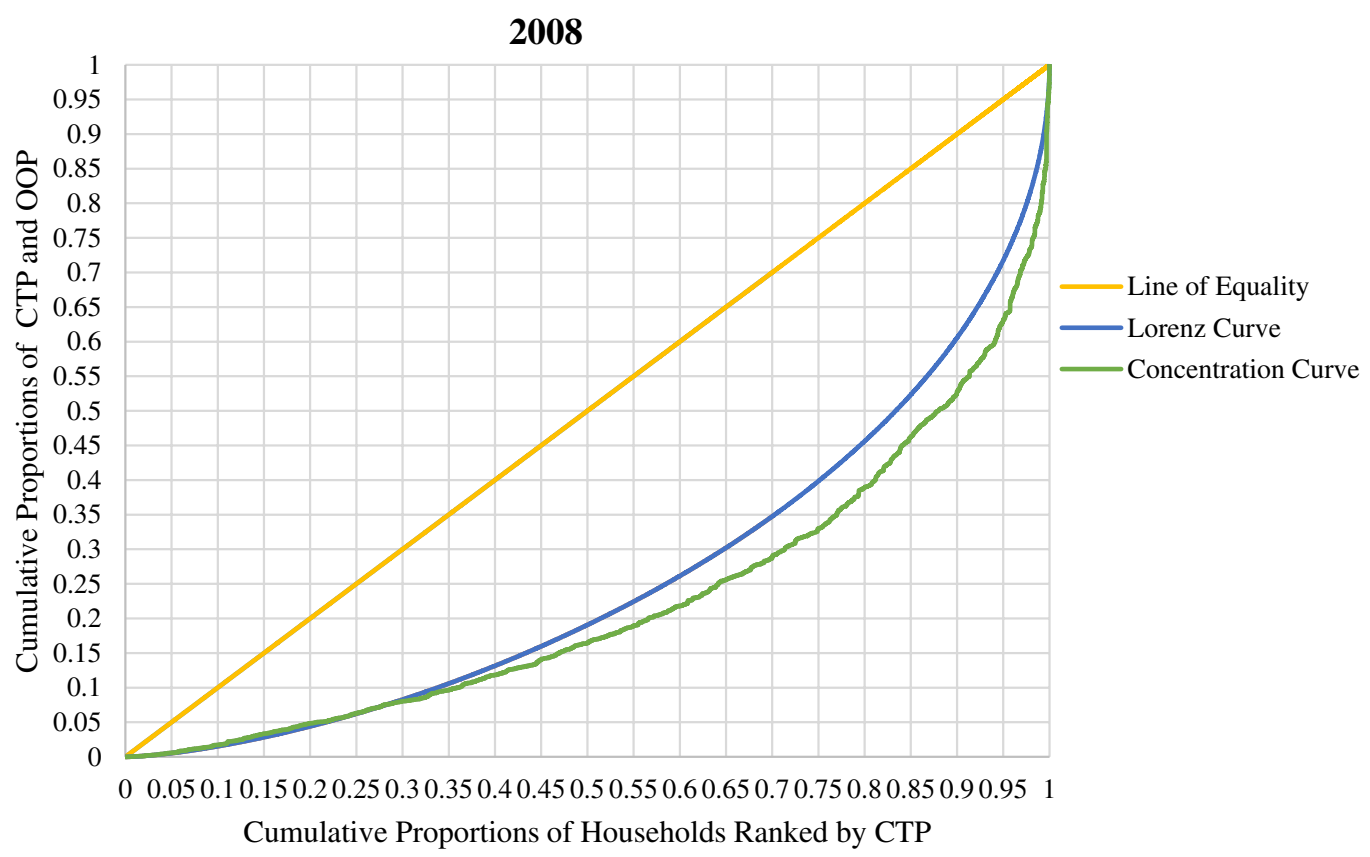

Figure 5. Lorenz and concentration curves for the year 2008. OOP, out-of-pocket health expenditure; CTP, capacity to pay.

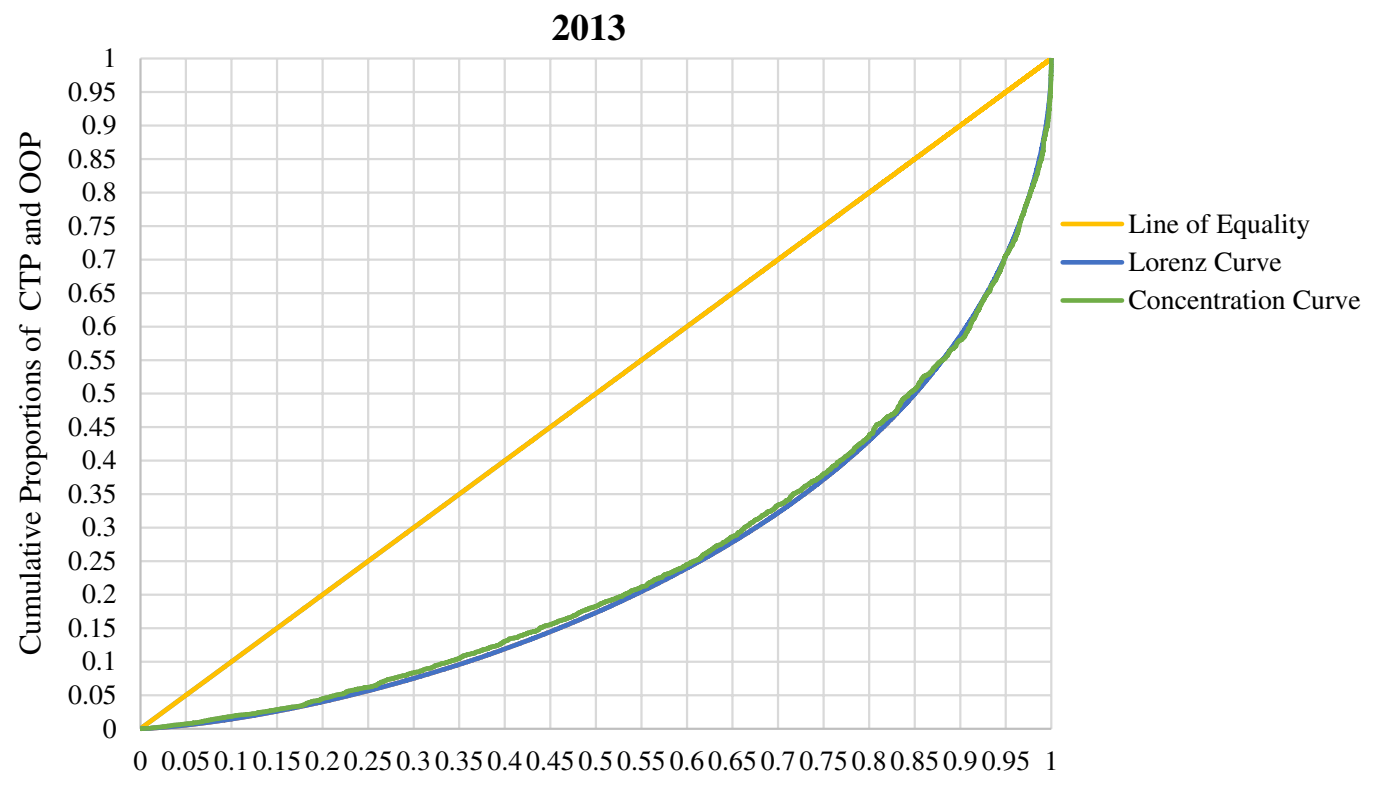

Cumulative Proportions of Households Ranked by CTP

Figure 6. Lorenz and concentration curves for the year 2013. OOP, out-of-pocket health expenditure; CTP, Capacity to pay.

insurance (Aran \& Hentschel, 2012). To achieve universal health coverage and to protect poor population groups, the Green Card program was expanded over the years, with the years 2003-2008 representing a rapid rise and successful implementation of the program (Aran \& Hentschel, 2012; Yenimahalleli-Yasar, 2011). However, despite extensions of the Green Card program, the Statistic of Income and Living Conditions survey reported that $18 \%$ of the population lacked health insurance coverage in 2006 (Erus et al., 2015;
Gursel, Darbaz, \& Karakoc, 2009). Establishment of the mandatory UHI system in 2008 paved the way for the SSI to inherit the Green Card program, thereby becoming the sole administrator in the health financing system. However, Erus et al. (2015) stated that the number of individuals covered by the Green Card program totaled 9,132,942 in 2007 and 9,895,000 in 2013, which represents a small rate of growth over the 6-year period.

Previous literature presents valuable information about the distribution of OOP health spending 
in Turkey. One of these studies (Oz, 2008), using the Kakwani index, examined the years 2003-2005 and observed a regressive pattern. Another study (Yardim et al., 2014) used the same index and analyzed the years 2003, 2006, and 2009, during which time the HTP was implemented and universal health coverage became a part of the program. These results indicated a deterioration in OOP health care expenditures throughout the years. It is evident that previous empirical evidence lacks information regarding the distributive pattern of OOP health care expenditures after the extension of the Green Card program and the unification of the health insurance system. Considering the scarcity of previous literature about this topic, this research provides an original contribution to knowledge regarding the distribution of OOP health care expenditures after the reforms to unify Turkey's health care financing system.

In this study, progressivity was analyzed using Lorenz and concentration curves and Kakwani-Suits index measures. Our results indicate that these two approaches are certainly compatible and that OOP health care expenditures have had an increasingly regressive pattern over the years between 2003 and 2015 in Turkey. Naturally, the distribution of OOP health expenditures is progressive in an egalitarian society (O'Donnell et al., 2008; Wagstaff et al., 1989). However, the regressivity of OOP expenditures differs for different financing models. A mildly progressive pattern for tax-financed systems can be observed in developed countries such as Denmark, Portugal, and the UK. The pattern is regressive, however, for social insurance systems (Wagstaff \& van Doorslaer, 1992), a pillar of Turkey's health insurance system (Yenimahalleli-Yasar, 2011). France, The Netherlands, and Spain show a regressive pattern in their social insurance systems. Lastly, private systems, such as those in Switzerland and the USA, have more regressive patterns (Wagstaff \& van Doorslaer, 1992). As evidenced by these statements, OOP payments are regressive in many developed European and OECD countries, and in the USA (De Graeve \& van Ourti, 2003). In most developed countries, considering health financing system differences and levels of development, OOP health expenditures are a regressive means of raising health care revenues (Wagstaff \& van Doorslaer, 1992). In countries with regressive patterns, all families, including the poor, spend a large share of their budget on OOP health care expenses (Makinen et al., 2000). The distributive pattern of OOP health expenditures is determined not only by health financing models but also by regulations in the insurance market (Wagstaff $\&$ Lindelow, 2008). There is a basic argument that insurance reduces financial risk and encourages people to seek care. Patients are faced with a moral hazard when the demand for care increases and the price is reduced through insurance (Feldstein, 1973). In this regard, insurance makes people more likely to use health care services by encouraging them to look for care when they become sick. However, there is little empirical evidence regarding the extent to which health insurance protects people from financial risk. The reasoning behind this is that the real-world effect of health insurance on risk reduction is largely unknown (Wagstaff \& Lindelow, 2008).

It would not be sufficient to raise OOP health expenditures, of course, unless the demand was price elastic (McGuire, 2000). Our study supports the idea that, after more than a decade experience of Turkish health reform, the financial burden of OOP health expenditures still falls on the shoulders of people with a low income. The curve and index approaches concur and show that an increasingly regressive trend appears after comprehensive insurance policies come into effect. These results were noticeable in the first year of health reform (2003), when the wealthy were more able to purchase insurance coverage than were people in low-income groups. Thus, a progressive OOP pattern was observed. In contrast, after 5 years of health reforms, the progressive patterns of OOP health expenditures changed to regressive ones. Despite claims that the poor are discouraged from seeking treatment until their illness becomes serious (Chaudhuri \& Roy, 2008) and that it is less expensive for society if people seek care before their illness becomes too serious, our empirical results support the idea that low-income households seek more care with an increase in insurance coverage. In other words, our results reveal that extensive insurance coverage, including poverty alleviation measures, increase the risk of high spending among poor population groups. This increasingly regressive pattern has coincided with poor economic growth in Turkey after 2007, which has forced people to spend more (Pamuk, 2007). Economic growth has altered the population and lifestyle dynamics of the Turkish people, and the nature of diseases has changed from infectious diseases to chronic illnesses (Okem \& Cakar, 2015). From an economic perspective, chronic diseases are costly and difficult to treat (Ghushchyan, Kolian, \& Manukyan, 2016). Frequent controls, as well as blood, cholesterol, and sugar checks, are necessary, which are available in more accessible health systems. Turkey has provided more accessible health service outlets in recent years, due to the HTP (Okem \& Cakar, 2015). However, knowledge is lacking about differences in insurance coverage, accessibility, and utilization of health care services between rural and urban parts of the country. Moreover, studies that examined equity in health care financing for middle- and low-income countries have stated that access to necessary and appropriate services is the biggest challenge to universal health coverage (i.e., Mills et al., 2012). Thus, the relationship between universal 
health coverage and accessibility to health services is certainly an area that needs further exploration. From another perspective, an increase in health literacy is expected to increase the level of health expenditures. Ozdemir, Alper, Uncu, and Bilgel (2010) found that the level of health literacy in Turkey has increased in recent years. This will lead to a better awareness of insurance coverage and, ultimately, low-income people spending more on their health. In conclusion, the results of this study emphasize that there is still room to protect financially disadvantaged population groups from the increasing burden of OOP health expenditures. Our results draw a current picture, in line with previous research, and highlight the increasingly prorich redistributive effect of OOP health expenditures in Turkey. In other words, the financial burden of OOP health expenditures lies with low-income individuals because of the unification of health financing and poverty alleviation strategies. Innovative financing mechanisms are necessary for collection, pooling, and purchasing to reduce poverty levels (Garg \& Karan, 2009). Experimenting with new payment mechanisms, in cooperation with the SSI, that control costs and increase provision efficiency can shift the burden of OOP health expenditures from low- to high-income groups. Additionally, full devotion to universal and equitable health care services, high-quality hospitals that ensure equal access to all citizens, regular monitoring of pharmaceutical and medical device prices, effective use of fiscal reserves created by economic growth to invest in health care, overcoming geographical barriers to high-quality health care services, and improving the level of health literacy are advisable strategies to improve the financial strength of the health care system. Lastly, to sustain Turkey's health system in the future, establishing a transparent, accountable, and independent SSI is necessary. Achieving a balance between the public and private sectors and obtaining and sustaining the financial protection of citizens are essential strategies for the future.

\section{Conclusion}

Based on our analysis, OOP health payments in Turkey are becoming more regressive (less progressive) under the unification of the health financing system. Thus, it is anticipated that this study will form a basis for future efforts of policymakers and professionals to eliminate the wide gaps in health financing that exist between the wealthy and the poor. Moreover, it is recommended that future studies analyze index results by focusing on urban and rural differences in insurance coverage, accessibility, effectiveness, and efficiency of health care services. Clearly, to understand and solve the problems of the health financing system in light of Turkey's welfare differences, a more thorough knowledge of these inequalities is essential. Future studies should analyze disease-specific OOP health expenditures by focusing on the costliest chronic diseases in Turkey. Continuous monitoring of OOP health expenditure distribution will enable health policymakers to detect departures from proportionality and identify inequalities.

\section{Acknowledgements}

This article is based on the $\mathrm{PhD}$ thesis written by Songul Cinaroglu (2017) entitled "The relationship between inequality and equity in health services financing and catastrophic health expenditures," approved by Hacettepe University, Institute of Social Sciences, Department of Health Care Management, Ankara, Turkey. A preliminary version of the study was presented at the International Health Policy Conference (IHPC) at the London School of Economics, February 16-19, 2017. The authors wish to acknowledge the constructive comments from participants at the IHP conference. Our thanks are also extended to the two anonymous reviewers of the study for their careful reading and insightful suggestions for enhancing the study's scientific contribution. The study was financed by The Scientific and Technological Research Council of Turkey (Tubitak), grant number 1059B141500020. The sponsor had no role in the study's design, the collection and analysis of the data, the writing of the report, or its submission for publication. The authors are grateful for the generous funding from Tubitak.

\section{References}

Acemoglu, D. \& Ucer, M. (2015). The ups and downs of Turkish growth, 2002-2015: Political dynamics, the European Union and the institutional slide. The National Bureau of Economic Research, NBER Working Paper No. 21608. Retrieved from http://www.nber.org/papers/w21608

Agartan, T. I. (2008). Continuity and change in Turkish health care system: The challenge of reform (A dissertation). Binghamton University, State University of New York, New York.

Agartan, T. I. (2012). Marketization and universalism: Crafting the right balance in the Turkish healthcare system. Current Sociology, 60(4), 456-471.

Akdag, R. (2011). Turkiye sağlıkta dönüşüm programı değerlendirme raporu 2003-2011 [Turkey health transformation program assessment report 2003-2011]. Ankara, Turkey: The Ministry of Health of the Republic of Turkey. Retrieved from https://sbu.saglik.gov.tr/Ekutuphane/Yayin/453

Akınc1, F., Mollahaliloglu, S., Gursoz, H., \& Ogucu, F. (2012). Assessment of the Turkish health care system reforms: A stakeholder analysis. Health Policy, 107(1), 21-30.

Anderson, J. E., Roy, A. G., \& Shoemaker, P. A. (2003). Confidence intervals for the Suits index. National Tax Journal, 56(1), 81-90.

Aran, M. \& Hentschel, J. S. (2012). Protection in good and bad times the Turkish Green Card health program. Policy Research Working Paper, 6178, WPS6178. Retrieved from http://documents.worldbank.org/curated/ en/258701468172771874/pdf/wps6178.pdf 
Atun, R., Aydin, S., Chakraborty, S., Sümer, S., Aran, M., Gurol, I., ... Akdag, R. (2013). Universal health coverage in Turkey: Enhancement of equity. Health Policy, 382(9886), 65-99.

Atun, R., Chaumont, C., Fitchett, J. R., Haakenstad, A., \& Kaberuka, D. (2016). Poverty alleviation and the economic benefits of investing in health systematic analysis and policy implications. Harvard T.C. Chan Harvard Kennedy School, Ministerial Leadership, Forum for Finance Ministers. Retrieved from https://cdn2.sph.harvard.edu/wp-content/ uploads/sites/61/2015/09/L-MLIH Health-economicgrowth-and-development Atun-and-Kaberuka 4-11-16.pdf

Bugra, A. \& Candas, A. (2011). Change and continuity under an eclectic social security regime: The case of Turkey. Middle Eastern Studies, 47(3), 515-528.

Bugra, A. \& Keyder, Ç. (2006). The Turkish welfare regime in transformation. Journal of European Social Policy, 16(3), 211-228.

Central Bank of the Republic of Turkey (CBRT). (2018). Retrieved from http://www.tcmb.gov.tr/wps/wcm/connect/ tcmb+en/tcmb+en

Cesur, R., Gunes, P. M., Tekin, E., \& Ulker, A. (2017). The value of socialized medicine: The impact of universal primary healthcare provision on mortality rates in Turkey. Journal of Public Economics, 150, 75-93.

Chaudhuri, A. \& Roy, K. (2008). Changes in out-of-pocket payments for healthcare in Vietnam and its impact on equity in payments, 1992-2002. Health Policy, 88(1), 38-48.

De Graeve, D. \& van Ourti, T. (2003). The distributional impact of health financing in Europe: A review. The World Economy, 26(10), 1459-1479.

De Maio, F. G. (2007). Income inequality measures. Journal of Epidemiology \& Community Health, 61(10), 849-852.

Deaton, A. (2003). Health, inequality and economic development. Journal of Economic Literature, 41(1), 113-158.

Elveren, A. Y. (2008). Social security reform in Turkey: A critical perspective. Review of Radical Political Economics, 40(2), 212-232.

Erus, B. \& Aktakke, N. (2012). Impact of healthcare reforms on out-of-pocket health expenditures in Turkey for public insurees. European Journal of Health Economics, 13(3), 337-346.

Erus, B., Yakut-Cakar, B., Cali, S., \& Adaman, F. (2015). Health policy for the poor: An exploration on the take-up of means-tested health benefits in Turkey. Social Science \& Medicine, 130, 99-106.

Feldstein, M. S. (1973). The welfare loss of excess health insurance. Journal of Political Economy, 81(2), 251-280.

Garg, C. C. \& Karan, A. K. (2009). Reducing out-of-pocket expenditures to reduce poverty: A disaggregated analysis at rural-urban and state level in India. Health Policy and Planning, 24(2), 116-128.

Ghushchyan, V., Kolian, S., \& Manukyan, S. (2016). Cost of chronic conditions for employees and employers in the United States. Value in Health, 19(A1-A318), 270-271.

Grignon, M. \& Kambia-Chopin, B. (2009). Income and the demand for complementary health insurance in France. IRDES (Institut de recherche et documentation en économie de la santé), Working Paper. Retrieved from http://citeseerx.ist.psu.edu/viewdoc/ download?doi $=10.1 .1 .319 .4357 \&$ rep $=$ rep1\&type $=$ pdf

Grignon, M., Perronnin, M., \& Lavis, J. N. (2008). Does free complementary health insurance help the poor to access health care? Evidence from France. Health Economics, $17(2), 203-219$.

Gursel, S., Darbaz, B., \& Karakoc, U. (2009). Yeşil kart: Türkiye'nin en maliyetli sosyal politikasının güçlü ve zaylf yanlart [Green Card scheme: Strengths and weaknesses of the most costly social policy of Turkey]. BETAM Research Notes, No. 039. Istanbul, Turkey: Bahcesehir University, BETAM.
Hone, T., Gurol-Urganci, I., Millett, C., Basara, B., Akdag, R., \& Atun, R. (2017). Effect of primary health care reforms in Turkey on health service utilization and user satisfaction. Health Policy and Planning, 32(1), 57-67.

Insurance Association of Turkey (IAT). (2015). Sektör raporu - 2015 [in Turkish]. (Sector report - 2015). Retrieved from https://www.tsb.org.tr/Document/Yayinlar/2015\%20 Y\%C4\%B11\%C4\%B1\%20Sekt\%C3\%B6r\%20Raporu\%20 T\%C3\%BCrk\%C3\%A7e.pdf

Kakwani, N. (1977). Measurement of tax progressivity: An international comparison. The Economic Journal, 87(345), 71-80.

Lambert, P. J. (1993). The distribution and redistribution of income: A mathematical analysis (2nd ed.). Manchester, UK: University Press.

Lambert, P. J. \& Pfähler, W. (1988). On aggregate measures of the net redistributive impact of taxation and government expenditure. Public Finance Review, 16(2), 178-202.

Makinen, M., Waters, H., Rauch, M., Almagambetova, N. Bitran, R., Gilson, L., ... Ram, S. (2000). Inequalities in health care use and expenditures: Empirical data from eight developing countries and countries in transition. Bulletin of the World Health Organization, 78(1), 55-65.

McGuire, T. G. (2000). Physician agency. In A. J. Culyer \& J. P. Newhouse (Eds.) Handbook of health economics (Vol. 1, pp. 461-536). Amsterdam, The Netherlands: Elsevier.

Mills, A., Ataguba, J. E., Akazili, J., Broghi, J., Garshong, B., Makawia, S., ... McIntyre, D. (2012). Equity in financing and use of health care in Ghana, South Africa, and Tanzania: Implications for paths to universal coverage. The Lancet, 380(9837), 126-133.

Morton, A. (2010). Bridging the gap: Health equality and the deficit framing of health. Health Economics, 19(12), $1497-1501$

O'Donnell, O., van Doorslaer, E., Wagstaff, A., \& Lindelow, M. (2008). Analyzing health equity using household survey data-A guide to techniques and their implementation (Chap. 16, pp. 187-196). Washington, DC: The World Bank.

OECD \& WB. (2008). OECD reviews of health systems: Turkey. Paris, France: OECD Publishing. Retrieved from https:// www.oecd-ilibrary.org/docserver/9789264051096-en.pdf?expires $=1531220104 \&$ id $=i d \&$ accname $=$ ocid $43023557 \&-$ checksum=3C4AA996DDD59ACB950F8119E775407C

Okem, Z. G. \& Cakar, M. (2015). What have health care reforms achieved in Turkey? An appraisal of the 'Health Transformation Programme'. Health Policy, 119(9), $1153-1163$.

Oz, E. (2008). Ulusal hanehalkı cepten sağlık harcamalarının finansmanda dikey hakkaniyet açısından değerlendirilmesi [Assessing vertical equity in national household outof-pocket health payments] (Doctoral thesis). Hacettepe University, Institute of Health Sciences, Health Care Administration, Ankara, Turkey.

Ozdemir, H., Alper, Z., Uncu, Y., \& Bilgel, N. (2010). Health literacy among adults: A study from Turkey. Health Education Research, 25(3), 464-477.

Pamuk, S. (2007). Economic change in twentieth century Turkey: Is the glass more than half full? (pp. 1-32). The American University of Paris, Working Paper, No.41. Retrieved from http://88.255.97.25/reserve/resfall14 15/ Int1410 Ecir Political Economy of Turkey ZOnis/1 Major Policy Phases.pdf

Pearson, M., Colombo, F., Murakami, Y., \& James, C. (2016). Universal health coverage and health outcomes. OECD Final Report, Paris. Retrieved from https://www.oecd. org/els/health-systems/Universal-Health-Coverage-andHealth-Outcomes-OECD-G7-Health-Ministerial-2016.pdf

Plat, D. (2015). Package - IC2. Retrieved from https:// cran.r-project.org/web/packages/IC2/IC2.pdf 
Schneider, P. (2004). Why should the poor insure? Theories of decision-making in the context of health insurance. Health Policy and Planning, 19(6), 349-355.

Seker, S. D. \& Jenkins, S. P. (2015). Poverty trends in Turkey. The Journal of Economic Inequality, 13(3), 401-424.

Sparkes, S. P., Bump, J. B., \& Reich, M. R. (2015). Political strategies for health reform in Turkey: Extending veto point theory. Health Systems \& Reform, 1(4), 263-275.

Suits, D. B. (1977). Measurement of tax progressivity. The American Economic Review, 67(4), 747-752.

Tatar, M. \& Kanavos, P. (2006). Health care reform in Turkey: A dynamic path in the wake of political consensus. Eurohealth, 12(1), 20-22.

Tatar, M., Ozgen, H., Sahin, B., Belli, P., \& Berman, P. (2007). Informal payments in the health sector: A case study from Turkey. Health Affairs (Millwood), 26(4), 1029-1039.

The Ministry of Health $(\mathrm{MoH})$ of Turkey. (2004). Turkey National Health Accounts 1999-2000. Ankara, Turkey: The Ministry of Health of Turkey, Refik Saydam School of Public Health.

Thomson, S. \& Mossialos, E. (2004). Private health insurance and access to health care in the European Union. European Observer: Newsletter of the European Observatory on Health Systems and Policies, 6(1), 1-4.

Turkish Statistical Institute (TurkStat). (2015). Database. TurkStat 2015 Household Budget Survey. Retrieved from http://www.TurkStat.gov.tr/

Undersecretariat of Treasury (UT) (Hazine Mustesarligi). (2013). Ozel Saglik Sigortalari Yonetmeligi [Regulation on Private Health Insurance]. Resmi Gazete. Retrieved from http:// www.resmigazete.gov.tr/eskiler/2013/10/20131023-1.htm

Wagstaff, A. (2002). Poverty and health sector inequalities. Bulletin of the World Health Organization, 80(2), 97-105.

Wagstaff, A. \& Lindelow, M. (2008). Can insurance increase financial risk? The curious case of health insurance in China. Journal of Health Economics, 27(4), 990-1005.
Wagstaff, A. \& van Doorslaer, E. (1992). Equity in the finance of health care: Some international comparisons. Journal of Health Economics, 11(4), 361-387.

Wagstaff, A., van Doorslaer, E., \& Paci, P. (1989). Equity in the finance and delivery of health care: Some tentative cross-country comparisons. Oxford Review of Economic Policy, 5(1), 89-112.

Wendt, C., Agartan, T. I., \& Kaminska, M. E. (2013). Social health insurance without corporate actors: Changes in self-regulation in Germany, Poland and Turkey. Social Science \& Medicine, 86, 88-95.

World Bank (WB). (2014). Turkey's transition: Integration, inclusion, institutions. The WB International Bank for Reconstruction and Development Washington D.C. Report No. 90509 - TR. Retrieved from https://openknowledge. worldbank.org/handle/10986/20691

$\mathrm{Xu}, \mathrm{K}$. (2005). Distribution of health payments and catastrophic expenditures. Methodology. World Health Organization-Geneva. EIP/HSF/DP.05.2. Retrieved from http://apps.who.int/iris/bitstream/handle/10665/69030/ EIP HSF DP 05.2.pdf? sequence $=1 \&$ isAllowed $=\mathrm{y}$

Yardım, M. S., Cilingiroglu, N., \& Yardım, N. (2014). Financial protection in health in Turkey: The effects of the Health Transformation Programme. Health Policy and Planning, 29(2), 177-192.

Yardim, M. S. \& Uner, S. (2018). Equity in access to care in the era of health system reforms in Turkey. Health Policy, 122(6), 645-651.

Yenimahalleli-Yasar, G. (2011). "Health Transformation Programme" in Turkey: An assessment. International Journal of Health Planning and Management, 26(2), 110-133.

Yildırım, H. \& Y1ldırım, T. (2011). Healthcare financing reform in Turkey: Context and salient features. Journal of European Social Policy, 21(2), 178-193.

Y1lmaz, V. (2013). Changing origins of inequalities in access to health care services in Turkey: From occupational status to income. New Perspectives on Turkey, 48, 55-77. 